\title{
Spiritual Culture Formation of Young Teachers in the System of Higher Education: The Way for Social Maturity Development
}

\author{
Zhannur Asetova ${ }^{1, \#, *}$, Saltanat Abildina ${ }^{1, \#}$, Albina Zh. Anesova ${ }^{2, \#}$, Zaure Kystaubayeva, ${ }^{3, \#}$ \\ and Anar Ryskeldina ${ }^{1, \#}$
}

${ }^{1}$ Karaganda State University Named after E.A. Buketov, Karaganda, Republic of Kazakhstan

${ }^{2}$ Pavlodar State University Named after S. Toraighyrov, Pavlodar, Republic of Kazakhstan

${ }^{3}$ Kazakh University of Technology and Business, Nur-Sultan, Republic of Kazakhstan

\begin{abstract}
The formation of spiritual culture should be based on the principles that guide every teacher in the implementation of their pedagogical skills in direct learning. The purpose of our study is to substantiate that young teachers' social maturity is characterized not only by the level of knowledge, development of their orientations but also by the degree of personal spiritual culture. We have applied the method of diagnosing a level of young teacher's social maturity development as a moderator in the search for spiritual values, but also a participant in the formation of personal spiritual culture directly at the student himself. Diagnostic sections have shown that the index of general social maturity of young teachers who shape the spiritual culture of students, is growing much faster compared to the young teachers who didn't show the activity of this kind. From the experimental data, it follows that young teachers' activity in creating a pedagogical environment of their school is an effective factor in the intensification of their social maturity formation. Investigating the problem of the formation of social maturity of the individual, a certain system of personal orientations develops, which serves as the basis of spiritual culture, which the student can choose. The authors show that such an opportunity can only be implemented with the teacher's integrated participation as a carrier of moral values. The study's novelty is determined by the fact that each of the participants in the educational process seeks to realize the share and type of moral views for the fulfillment of their personal interests. The study's practical significance is determined by the fact that spiritual culture can be based not only on its private but also on its public perception.
\end{abstract}

Keywords: Social relations assimilation, level of knowledge, spiritual culture, pedagogical environment.

\section{INTRODUCTION}

Studying the social maturity of a young teacher's personality, we face the need to analyze the interaction of the various young teacher's relationships with those complex systems in which they live and which form their world. In this direction, it is necessary to identify functional connections and, first of all, to substantiate social maturity, as the individual systemic quality. Social maturity as the systemic quality is an integral quality of the young teacher's personality that is inaccessible to direct observation and can only be justified by the scientific analysis of those systems to which this person directly or indirectly belongs, as well as the laws that this person is subordinated to [1].

Researching young teacher's social maturity is relevant due to the lack of fundamental works in foreign pedagogical and psychological paradigm in this aspect. In our understanding, the social maturity of the young teacher's personality should be characterized not only by the level of knowledge, not by the development of their orientations but by the degree of assimilation of

\footnotetext{
*Address correspondence to this author at the Karaganda State University Named after E.A. Buketov, Karaganda, Republic of Kazakhstan; Tel: +77212356398; E-mail: zh.asetova5047-1@tanu.pro

"These authors are equally contributed.
}

social relations and their realization in pedagogical activity [2]. Thus, diagnosing the young teachers' social maturity allows organizers of the educational process and teachers to perform management and quality control over the effectiveness of educational activities [3].

Under the social maturity of a young teacher, we understand a certain degree of development of their personality, which contributes to the creative development of different types of culture, and also creates the opportunity to most effectively benefit from the surrounding participation in various activities. In this research, under the notion of "young teachers," we mean the teachers who work in educational institutions in the first five years after graduating from a higher educational institution [4].

The formation of the young teacher's social maturity is intended to integrate the objective patterns of the system with the goals that are put forth by the system of school education work and the individual teacher as its component [5].

The social maturity of a young teacher's personality is, firstly, an indicator of the level of their development, and secondly, characterizes the focus on socially significant goals, shows the degree of correlation of 
personally significant motives of activity with motives necessary from the point of view of society, and thirdly, social maturity finds its manifestation primarily in an active life position [6].

We consider social maturity to be "a holistic characteristic of the individual development, taking into account the professional, labor, civil-political, moral and cultural maturity, which together create a new systemic quality of the person" [7]. Humans' social nature is closely linked with the properties and characteristics of them as a cultural entity. The moral, political, professional, and other types of human culture educators see as the main content of the integral individual personality development, social maturity. This approach allows us to distinguish the corresponding types of person's social maturity - moral maturity, political, professional, environmental, and others. This means that the model of social maturity of the individual should reveal the content of social selfdetermination, social activity, and social responsibility through the content of the basic components of human culture.

\section{MATERIALS AND METHODS}

In a pedagogical study of the social maturity of an individual, it is not enough to only register the final process. It is necessary to establish how a person achieves the final result and why one or the other situation helps or prevents the person from realizing the appropriate qualities in a particular activity.

To determine the level of formation of social maturity of the individual M. P. Lebedyk proposed uniform for all young people diagnostic method whereby studying the degree of detection of each of the three characteristics criterion results in the comparative analysis is advisable to show as a quantitative index [8].

According to this method, an index is given by the analytic function

$\mathrm{I}=\mathrm{F}\left(\mathrm{x}_{\mathrm{i}}\right)$,

where $I$ is the index, $x_{i}$ is the set of empirical indicators; $F$ is the conversion symbol to which subjects the set $x_{i}$ during the conversion into an index.

During the study, a modified version of the experiment "ex post facto" was used, the essence of which was to align the groups of young teachers under study. In the process of alignment, we took into account the year and place of birth of young teachers, marital status, gender, the presence of social experience.

In the studies, the difference between the index and the indicator is that the index makes it possible to compare indicators that are directly disproportionate. The index as a form of generalization of the number of indicators is an estimated normalized number [9].

Quantitative criteria are experimentally separated intervals of the values of social activity indices, responsibility, and self-determination ones of the individual. The variants of their combination form a specific number of levels of formation of the individual's social maturity.

The experimental values of each index vary from 1 to 5 . We allocate three intervals of numerical values of the index as "high", "average", and "low". Frames of these intervals characterize a certain level of social maturity of the individual, which has a quantitative and qualitative explanation.

The first ("high") level of formation of social maturity of a person characterizes it, if within the frame of values "high interval" falls at least one of the values of the indices - self-determination, activity or responsibility (5.0-4.01).

The second ("average") level of formation of social maturity of a person characterizes the future specialist, if within the limits of values of the "average interval" falls at least one of the values of the indices of selfdetermination, activity, and responsibility (4.0-3.01).

The third ("low") level of social maturity of a personality of a future specialist characterizes one of the values of those mentioned above three and does not fall into any of the two intervals mentioned above $(3.0-1.4)$

The content of the criteria is theoretically derived from the social position of the individual and the social situation in which their social maturity is formed. It is the dynamism of social position that involves criteria that are specified through the content of social selfdetermination, social activity, and social responsibility in the structure of the individual and one's practical activities.

The study of the dynamics of the development of social maturity of the individual (on the example of pedagogues and students) has been performed for a 
long time (1995-2017). According to the results of the diagnostic section of the personal development of young teachers of some schools of Kirovograd region, conducted during 1995-2017 years, the highest values of social maturity in schools have those young teachers who actively influence the development of the school environment. For comparative analysis, we use the diagnostic sections of 2010-2011 and 2017.

The diagnostic section in 2017 showed that the index of general social maturity of young teachers who form the environment is growing much faster compared to young teachers who make up the control group (experimental results). The diagnostic section of 2017 was made mainly with young teachers who were part of the sampled diagnostic segment of 2010. Experimental work has been carried out since 1989. During this period, eleven diagnostic sections were conducted. We used the results of the first sections as a zero section.

The pedagogical experiment of determining young teacher's social maturity has been multi-leveled and multidimensional. The essence of the experiment is in the formation of two groups of schools, where the first group - are experimental Kropyvnytskyi schools 5, 11, 21 , and the second one - control Kropyvnytskyi schools $34,16,24,32$. In the schools belonging to the first group, conditions of intensive formation of young teacher's social maturity, which are: formation of the latter in the collective; the influence of pupil's social maturity onto the growth of social maturity of teacher's personality; continuous qualification raise; dependence of young teacher's social maturity on the pedagogical culture. The control group comprise the

\section{RESULTS}

The definition of the problem of a socially mature person through the prism of the interconnection of external and internal influences on its development is associated with the actualization of ideological issues, and also, to a large extent, with the tasks of taking into account the increasing importance of the subjective factor in social life, which find expression in research the ratio of personality and society, personality as a subject of culture, in attempts to build a personality theory and the pedagogical aspect of its implementation, from how socially mature a person is so that they will determine their existence in real life [10].

The study results indicate that with each subsequent year of activity in the school, a prerequisite is created for the formation of the young teacher's social maturity and self-realization (Tables $\mathbf{1}, 2$ ). The most noticeable influence the school environment makes on the formation of features, which is one of the main conditions for improving self-realization of the individual - the ability to organize their own work.

The problem of upbringing the social maturity of a person touches upon the issue of their formation,

Table 1: The Generalized Index Values of Social Maturity of Subgroups of Young Teachers who Actively Influenced and did not Influence the Environment (in Absolute Terms), as of January 2017

\begin{tabular}{|c|c|}
$\begin{array}{c}\text { Young teachers who are actively influencing the environment }(\mathbf{N} \\
\mathbf{= 1 2 0} \text { people })\end{array}$ & $\begin{array}{c}\text { Young teachers who are not influencing the environment }(\mathbf{N}=\mathbf{1 2 0} \\
\text { people })\end{array}$ \\
\hline \hline 4.67 & 3.84 \\
\hline
\end{tabular}

Table 2: Frequency Distribution of Young Teachers with the Indicated Intervals of the Social Maturity Index (Section I - January 2010, Section II - January 2017)

\begin{tabular}{|c|c|c|c|c|c|c|c|c|c|c|}
\hline $\begin{array}{c}\text { Young teachers who are actively influencing the } \\
\text { environment }(\mathrm{N}=120 \text { people })\end{array}$ & Section I & - & - & 14 & 8 & 17 & 14 & 17 & 32 & 18 \\
\hline $\begin{array}{l}\text { Young teachers who are actively influencing the } \\
\text { environment } \\
\qquad(\mathrm{N}=120 \text { people })\end{array}$ & Section II & - & - & 4 & 4 & 6 & 11 & 16 & 22 & 57 \\
\hline $\begin{array}{l}\text { Young teachers who are not actively influencing the } \\
\text { environment } \\
\qquad(\mathrm{N}=120 \text { people })\end{array}$ & Section I & - & 4 & 7 & 18 & 27 & 34 & 14 & 11 & 5 \\
\hline $\begin{array}{l}\text { Young teachers who are not actively influencing the } \\
\text { environment } \\
\qquad(\mathrm{N}=120 \text { people })\end{array}$ & Section II & - & - & 4 & 9 & 17 & 13 & 49 & 16 & 12 \\
\hline Scale of intervals (Index of social maturity) & & 1.0 & 1.5 & 2.0 & 2.5 & 3.0 & 3.5 & 4.0 & 4.5 & 5.0 \\
\hline
\end{tabular}


depending on the purposeful pedagogical influence. Self-determination can be structurally distinguished as social, professional, socio-political, family, communication respectfully to the main spheres of life. V.F. Safin notes that the central here is social selfdetermination, which he defines as "integration of youth into the main components of the social structure of society" [11]. Additionally, he accentuates that social self-determination is directly related to the vocational choice, resulting not only in a profession but also a new social microenvironment that young people enter [11]

The data shows that the activity of young teachers in creating a pedagogical environment of their school is an effective factor in the intensification of the formation of social maturity of their personality.

A socially mature person realizes the social selfdetermination, and through it, responsibility and activity are involved in the interaction with the outside world. The source of such activity is social needs. In social needs, there is a certain state of the psyche. To restore the performed by the psyche achievements and disadvantages, it is necessary to restore the costs of the respective forces by identifying social activity, depending on a certain level of social selfdetermination of the personality of the person. In society, these needs largely depend on the content of the education received, on the impact of the surrounding social environment [12].

As it follows from the above stated experimental data, the second diagnostic section has shown that the generalized index of social maturity of young teachers forming the environment grows at a much faster rate than young teachers who make up the control group, as shown in Table 1. The data in Table 1 shows that the activity of young teachers in creating a pedagogical environment of their school is an effective factor in the intensification of individual social maturity formation.

The school environment we are investigating is primary concerning the school and teachers in particular. Unlike the informal association, the school environment is formal. Socially important tasks that are inherent in any formal group are realized through the real participation of members of the group in various activities. These activities are both specific and nonspecific for the social role that this group performs. For the school environment, specific educational and cognitive activities, educational activities, non-specific social work, joint rest. It is important to emphasize that such a division is arbitrary since non-specific kinds can be entirely attributed to specific. Thus, such a circumstance has led us to an experimental study of the extent to which each young teacher is involved in these activities in the life of the school environment.

The results of the study indicate that with each subsequent year of activity in the school, a prerequisite is created for the formation of the young teacher's social maturity and self-realization. The most noticeable influence the school environment makes on the formation of features is one of the main conditions for improving the self-realization of the individual - the ability to organize their own work.

\section{DISCUSSION}

Throughout human life, there is a constant shift of emphasis from the individual to the social in human nature (and often without the individual). At the same time, according to R. Welder, even though a person possesses specific, totally distinctive traits of character, intellect, way of life, etc., upon joining a group, becomes a part of its collective "soul" and receives an ability to think and act now differently [13]. The scientist also emphasizes here that the production of collective ideas is only possible by individuals gathered in a group.

For O. M. Leontiev, "activity is a polar, non-active unit of life of the physical, material subject" [14]. And further: "Activity is not a reaction and not a set of reactions, but a system that has a structure, its internal transitions, and transformation, its development" [14]. In this understanding of the activity, it cannot be any human activity, but only such, where the subject of the action is the subject of any need. Only in this case, activity remains a "unit" of human life and begins to dictate to the subject that one must reflect from the outside world, what knowledge and skills one must master, in order to solve problems of life successfully, and not only adaptive but also creative (creating conditions of life).

Personality, by the definition of L. S. Vygotsky, is a holistic psychic system, which performs certain functions and arises in a person to serve these functions [15]. The main functions of the individual the creative development of social experience and the inclusion of rights in the system of social relations. All sides of the person are manifested only in activities and in relationships with other people. The person exists, is manifested and formed in the activity and communication. Hence, the most important 
characteristic of the individual - the social condition of a person, all one's manifestations associated with the life of the surrounding people.

L. S. Vygotsky believed development was carried out in an inseparable internal connection with education, in the course of its progressive movement. "The cooperation of a child and an adult - a central point in the educational process, because the mental development of the child is carried out through the formation of its higher mental functions with the help and with the participation of adults, that is, through the development of children" [16].

We consider the social formation of personality as a complex process of adaptation of the younger generation to life, a certain social community. Therefore, in psychological and pedagogical publications, a person's social maturity is more often interpreted as a holistic cycle of individual development of a person, which includes childhood, youth, and old age. This implies that there is a point of reference - the minimum social maturity of the individual [17].

Personality is considered by pedagogues as an individual, specific entity. In philosophy, "singular" (separate, individual) refers to a concept that captures individual things, phenomena, which are characterized by the corresponding spatial and temporal boundaries, corresponding to the quality. "... the individual exists only in a separate, which is the dialectical unity of the individual and the general" [18].

The existence of an individual can be imagined as the unity of a variety of existing social phenomena. According to the concept of E. V. llyenkov: "body" of a person who acts like a person - is its organic body, together with those artificial organs, which it forms from the substance of the external nature, "elongating" and repeatedly increasing the natural organs of its body and thereby complicating their mutual relations with other individuals, revealing their "essence" [19].

By nature, the person as a social entity, at the same time, reproduces the imprint of humans' biological organization. Necessary and sufficient condition for the birth of a person is a social factor, where the participation of human in public life, their relationship with other people are characterized by activity, selfexpression, and self-determination. These personality qualities determine the degree of social maturity of the individual [20].

The definition of the problem of a socially mature person through the prism of the interconnection of external and internal influences on the development is associated with the actualization of ideological issues, and also, to a large extent, with the tasks of taking into account the increasing importance of the subjective factor in social life, which find expression in research the ratio of personality and society, personality as a subject of culture, in attempts to build a personality theory and the pedagogical aspect of its implementation. From how socially mature a person is, they will determine their existence in real life [21].

The credible reality in which a person exists is the one that historically appeared as a set of forms of joint activity, within which the wealth of material and spiritual value of culture is stored and transmitted from generation to generation and accumulated by humankind. According to L. S. Vygotsky, the cultural development of a person is realized in a certain sequence: "... any psychic function necessarily passes an external stage in the development because it is an initial social function" [16]. Consequently, close interpersonal contacts are established in connection with the greater penetration of people's interactions. On this basis, there is an increase in the young person's independence, the complication of their inner world, and the formation of their properties.

According to the characteristics by O. G. Asmolov, "activity determines the personality, but the person chooses the activity that determines it" [22]. Therefore, at each age stage, it is necessary to form a complex, multidimensional activity, rather a dynamic system of activities, each of which solves its special task that meets social expectations.

Human activity is realized in three spheres characteristic to them - labor, communication, and cognition [23]. Therefore, when determining the main activity, it is necessary to indicate the three sides of its content, which is achieved by establishing the ratio of the three types of activity, rather than emphasizing one of them.

We proceed from the division not onto material and spiritual culture, but rather onto the kinds: moral, labor, political, ecological, etc. This implies the unity of material and spiritual. Mastering the individual culture, which is the basis worldview achieved the purposeful formation of socially significant qualities, especially social activity, responsibility, and self-determination. These personality traits ensure the inclusion of a person in a real-life reality [24]. Based on this mechanism, the transfer of wealth of material and 
spiritual culture, accumulated by humanity, from generation to generation, and the formation of new cultural values is achieved.

When forming a person's social maturity, a certain system of personality orientation for the values available in society is developed. The essence of the problem of constructing a value orientation model is to isolate that property of the system of "personality society", which is system-based. The most important for a person is social installations, which determine the purpose and means of its activities [25].

The growth of levels of organization of personality necessarily leads to a change in the purpose of life, set by the person. Any level of higher-order (quality) is manifested in the self-determination of a person [26]. An important socio-psychological regularity, personality development, is that the person is the carrier and the spokesman for social and collegial interests. Nevertheless, one can only be their conscious subject at a certain level of social maturity, when the person self-determined and, in this regard, improves the activity and increases responsibility.

\section{CONCLUSION}

Investigating the problem of the formation of social maturity of the individual, we have shown that while forming the social maturity of a person, a certain system of personality orientations for the values available in society is developed. The essence of the problem of constructing a model of value orientations of the individual is to isolate that property of the system of "personality - society", which is system-based. The most important for a person is social installations, which determine the purpose and means of their activities.

To study the experience of young teacher's social maturity formation, we have used the comparative analysis of young teacher's social maturity frequency division of indices and its contents, depending on the presence of influence on the development of the school environment.

To analyze interrelation between collective school development and young teacher's social maturity formation, we have used a value-related mutual influence. In the experimental work, we have performed research on young teacher's social maturity formation as a part of a local social microstructure, which is the school collective.
Social activity, responsibility, and self-determination make it possible to talk about the individual's social maturity as an organic unity of these personality traits at a higher level of development. The use of diagnostic techniques and sociological tools allowed us to define the life self-determination of the young people who are studying as the one mainly characterized by the professional orientation, which is connected to become a skilled worker and to get out of the situation of "inferiority" as a member of society. Social selfdetermination, in its turn, characterizes a person as the personality. This determines the individuality, value, professional orientation, etc. A person strives to make the right life choice, while influencing the processes of society's vital functions at a certain level of their competence, to feel the influence of society.

\section{ACKNOWLEDGEMENT}

None.

\section{REFERENCES}

[1] Kim LE, Jörg V, Klassen RM. A meta-analysis of the effects of teacher personality on teacher effectiveness and burnout. Educational Psychology Review 2019; 31(1): 163-195. https://doi.org/10.1007/s10648-018-9458-2

[2] Albrecht K. Social Intelligence. The New Science of Success. San Francisco: Jossey-Bass 2006.

[3] Rimm-Kaufman S, Hamre B. The role of psychological and developmental science in efforts to improve teacher quality. Teachers College Record 2010; 112(12): 2988-3023.

[4] Maslou A. Motivation and personality. Saint Petersburg: Yevraziya 2001.

[5] Alarcon G, Eschleman KJ, Bowling NA. Relationships between personality variables and burnout: A meta-analysis. Work and Stress 2009; 23(3): 244-263.

https://doi.org/10.1080/02678370903282600

[6] Brown CG. A systematic review of the relationship between self-efficacy and burnout in teachers. Educational and Child Psychology 2012; 29: 47-63.

[7] Radul VV. Personality's social maturity. Kharkiv: Machulin 2017.

[8] Lebedyk MP. Public evaluation of pedagogical university students based on personality's social maturity. Poltava: PGPI 1987.

[9] Liashenko RO. Category characteristics of personality selfdetermination. Innovative Solutions in Modern Science 2017; 2(11): 1-14

[10] Mulyar VI. Personality's self-realization as a social process: (methodological, sociological aspect). Kyiv: T. Shevchenko KGU 1990.

[11] Safin VF. Psychology of personality self-determination Sverdlovsk: Sverdlovskiy Ped institute 1986.

[12] Fromm E. Human for oneself. Moscow: Progress 1992.

[13] Welder RK. On issue of the subconscious aggressiveness phenomenon. Social Sciences and Modernity 1993; 3: 183190.

[14] Leontiev AN. Activity. Consciousness. Personality. Moscow: Politizdat 1997 
[15] Vygotsky LS. Selected psychological studies. Moscow: APN RSFSR Publishing 1956.

[16] Vygotsky LS. Psychology of art. Rostov-on-Don: Feniks 1998.

[17] Radul VV. Teacher's personality social maturity: factors of formation. Kyiv: Vyshcha Shkola 2008.

[18] Buchanan J, Prescott A, Schuck S, Aubusson P, Burke P. Teacher retention and attrition: Views of early career teachers. Australian Journal of Teacher Education 2013; 38(3): 112-129.

https://doi.org/10.14221/ajte.2013v38n3.9

[19] Ilyenkov EV. What is a personality? Moscow: Politizdat 1984.

[20] Sartr ZhP. Being and nothing. Experience of phenomenological ontology. Moscow: Progress 2000.
[21] Goldstein K. Human nature in the light of psychopathology. Cambridge: Harvard University Press 2014.

[22] Asmolov AG. Psychology of personality. Moscow: MGU Publishing 1990.

[23] Platonov KK. A brief vocabulary of psychological concepts system. Moscow: Vysshaya Shkola 1984.

[24] Levin K. The relationship of local education systems with the nationwide. Moscow: Pedagogika 1974.

[25] Frankl V. Human in search of meaning. Moscow: Progress 1990.

[26] Freyd Z. Psychoanalysis. Religion. Culture. Moscow: Progress 1992

Received on 02-04-2020

Published on 27-11-2020

DOI: https://doi.org/10.6000/2292-2598.2020.08.04.7

(C) 2020 Asetova et al.; Licensee Lifescience Global.

This is an open access article licensed under the terms of the Creative Commons Attribution Non-Commercial License (http://creativecommons.org/licenses/by-nc/3.0/) which permits unrestricted, non-commercial use, distribution and reproduction in any medium, provided the work is properly cited. 